\title{
Políticas públicas indigenistas: dominação estatal
}

\author{
Indigenous public policies: state domination \\ Políticas públicas indigenistas: dominación estatal
}

\section{Resumo}

Os povos indígenas sofrem uma relação de dominação desde o período colonial. Tal dominação ocorria, inicialmente, por parte da Igreja Católica, que possuía a responsabilidade pelo aldeamento e pela catequização dos indígenas. Em seguida, a dominação passa a ser realizada pelo Estado, responsável em institucionalizar ou legitimar direitos, mas também deveres à sociedade, podendo levar ou não em consideração as peculiaridades socioculturais das comunidades indígenas no momento da formulação das políticas públicas. Observa-se que, mesmo havendo políticas públicas indigenistas, elas ou são mal desenhadas ou são insuficientes, de modo que, muitas vezes, contribuem para a extinção das diferenças entre os próprios povos indígenas e entre esses e os não indígenas, uma vez que não são respeitados seus direitos culturais, territoriais, educacionais, pluriétnicos, de saúde, de autodeterminação, etc. Diante disso, o objetivo desta pesquisa foi identificar as características observadas na relação entre o Estado e as populações indígenas em sua interface com as políticas públicas. Para tanto, realizou-se uma revisão narrativa de literatura em que foram destacados: o ciclo de gestão e a especificidade das políticas públicas na realidade indígena; as nuances culturais, sociais e econômicas das populações indígenas na interação com o Estado; e uma síntese dos diálogos e conflitos do Estado e sociedade (indígena) em políticas públicas relevantes para este grupamento social. Com isso, identificou-se participação nula ou baixa dos povos indígenas em várias etapas do fluxo da política pública, ao passo que esses buscam maior inserção no processo político-administrativo.

Palavras-chave: Direitos sociais; Políticas públicas indigenistas; Protagonismo indígena.

\begin{abstract}
Indigenous peoples have suffered a relationship of domination since the colonial period. Such domination occurred, initially, on the part of the Catholic Church, which had the responsibility for the catechization of the indigenous people. Then, domination becomes the responsibility of the State, responsible for institutionalizing or legitimizing rights, but also duties to society, which may or may not take into account the socio-cultural peculiarities of indigenous communities when formulating public policies. It is observed that, even if there are indigenous public policies, they are either poorly designed or insufficient, so that, many times, they contribute to the extinction of the differences between the indigenous peoples themselves and between these and non-indigenous peoples, since they their cultural, territorial, educational, multi-ethnic, health, self-determination, rights are not respected. Therefore, the objective of this research was to identify the characteristics observed in the relationship between the State and the indigenous populations in their interface with public policies. To this end, a narrative literature review was carried out in which the following were highlighted: the management cycle and the specificity of public policies in the indigenous reality; the cultural, social and economic nuances of indigenous peoples in their interaction with the State; and a synthesis of the dialogues and conflicts of the State and society (indigenous people) in relevant public policies for this social group. As a result, zero or low participation of indigenous peoples was identified in various stages of the flow of public policy, while they seek greater insertion in the political-administrative process.
\end{abstract}

Keywords: Social rights; Indigenous public policies; Indigenous protagonism. 


\begin{abstract}
Resumen
Los pueblos indígenas han sufrido una relación de dominación desde el período colonial. Tal dominación se dio, inicialmente, por parte de la Iglesia Católica, que tenía la responsabilidad de la catequesis de los indígenas. Entonces, la dominación pasa a ser responsabilidad del Estado, responsable de institucionalizar o legitimar derechos, pero también deberes con la sociedad, que puede o no tener en cuenta las peculiaridades socioculturales de las comunidades indígenas a la hora de formular políticas públicas. Se observa que, si bien existen políticas públicas indígenas, estas están mal diseñadas o son insuficientes, por lo que, muchas veces, contribuyen a la extinción de las diferencias entre los propios pueblos indígenas y entre estos y los no indígenas, ya que no se respetan sus derechos culturales, territoriales, educativos, multiétnicos, sanitarios, de autodeterminación. Por tanto, el objetivo de esta investigación fue identificar las características observadas en la relación del Estado con las poblaciones indígenas en su interfaz con las políticas públicas. Para ello, se realizó una revisión narrativa de la literatura en la que se destacaron: el ciclo de gestión y la especificidad de las políticas públicas en la realidad indígena; los matices culturales, sociales y económicos de los pueblos indígenas en su interacción con el Estado; y una síntesis de los diálogos y conflictos del Estado y la sociedad (indígena) en políticas públicas relevantes para este grupo social. Como resultado, se identificó nula o baja participación de los pueblos indígenas en diversas etapas del flujo de las políticas públicas, mientras buscan una mayor inserción en el proceso político-administrativo.
\end{abstract}

Palabras clave: Derechos sociales; Políticas públicas indígenas; Protagonismo indigena.

\title{
1. Introdução
}

A decisão política é definida como a preferência em meio a um amplo leque de decisões, levando-se em conta a hierarquia de importância para se tomar a melhor escolha. Por outro lado, a política pública é definida, necessariamente, como um amplo leque de decisões e diferentes ações para colocar em prática as escolhas já tomadas. Em outras palavras, a política pública é um conjunto de decisões e não uma decisão em particular. Rua (2013, p. 8) declara que "[...] embora uma política pública implique decisão política, nem toda decisão política chega a constituir uma política pública”.

O conceito de política pública tem como seus fundadores Harold Lasswell, David Easton, Herbert Simon e Charles Edward Lindblom, os quais definem que as políticas públicas são estudos da política, a qual analisa os efeitos das atividades do governo e a influência delas na vida dos cidadãos. Em suma, a acepção de política pública baseia-se nas atividades que o governo escolhe fazer ou não fazer, sendo ele responsável por todos os impactos derivados de sua ação ou inação (Dye, 2016).

As políticas públicas são criadas para a resolução dos problemas oriundos da sociedade, com o intuito de garantir resultados em diferentes áreas, como saúde, educação e meio ambiente, isto é, a política pública é estabelecida pelo governo por meio de um conjunto de ações, metas e planos para alcançar o interesse público e o bem-estar da sociedade, sendo de responsabilidade dos governantes ou dos tomadores de decisões selecionar as ações prioritárias, a fim de suprir as demandas ou expectativas da sociedade na realização de algo (Lopes, Amaral \& Caldas, 2008).

Wandscheer e Bessa (2009) destacam que o surgimento das políticas públicas advém da necessidade de garantir a satisfação dos interesses comuns de grupos ou segmentos da sociedade. Quando as políticas são voltadas a um grupo de indivíduos que apresentam necessidades semelhantes, elaborar um plano de ação para atender tais demandas apresenta-se como meio mais acessível para atingir um maior número de cidadãos.

De acordo com Rodrigues e Thé (2012, p. 8) “A sociedade brasileira durante o processo constituinte considerou que existem no interior do país diversos grupos culturalmente diferenciados que contribuíram para a constituição da nacionalidade brasileira". Esses grupos são denominados como comunidades ou povos tradicionais - os quais desenvolvem suas próprias culturas, costumes e formas de vida. Essas comunidades buscam reivindicar direitos que, em sua maioria, foram negados pelo Estado, além de buscar compreender os motivos pelos quais um país tão heterogêneo em sua composição ainda permita que seus povos se encontrem excluídos da formulação de políticas públicas (Silva Júnior \& Souza, 2009).

No contexto das políticas públicas direcionadas aos povos indígenas, o poder público se depara com uma multiplicidade de demandas e necessidades, as quais se justificam pela diversidade sociocultural que estes povos representam. Logo, surge a exigência de análises mais complexas para o desenvolvimento de políticas especializadas. No entanto, muitas 
das políticas concebidas para este público não consideram as particularidades dos povos indígenas, colocando-os na mesma realidade de não-indígenas, o que acarreta baixa efetividade (Wandscheer \& Bessa, 2009).

Diante disso, pautou-se como problema desta pesquisa "quais as características observadas na relação entre o Estado e as populações indígenas em sua interface com as políticas públicas? A partir deste problema, foi definido o seguinte objetivo geral: identificar as características observadas na relação entre o Estado e as populações indígenas em sua interface com as políticas públicas. Com a fragmentação do objetivo geral, foram definidos os seguintes objetivos específicos: (1) definir as etapas da política pública; (2) descrever as especificidades culturais, sociais e econômicas das populações indígenas na interação com o Estado; e (3) sintetizar diálogos e conflitos do Estado e sociedade (indígena) em políticas públicas relevantes para este grupamento social.

A justificativa desta pesquisa se encontra na importância de conhecer os processos do ciclo de gestão das políticas públicas para as comunidades indígenas, além de analisar a relação que ocorre entre essas e o Estado, pois, devido às peculiaridades apresentadas por tais comunidades, há a necessidade de políticas públicas especificas para o fornecimento de bens e serviços públicos de educação, saúde, bem-estar e, principalmente, de regulação e salvaguarda de políticas territoriais.

\section{Metodologia}

Esta pesquisa é classificada como qualitativa, pois realiza a análise de registros textuais - uma das fontes de evidência qualitativa - em busca de interpretações sobre os fenômenos estudados (Patton, 2015). A fim de atingir os objetivos propostos pela pesquisa, foi realizada uma revisão narrativa de literatura, a qual seguiu o "modelo geral de revisão narrativa" elaborado por Ferrari (2015). Este modelo busca, juntamente com o problema e com os objetivos da pesquisa, evidenciar os vieses de seleção e a estratégia de busca empreendidos. No Quadro 1, são apresentados os detalhes da etapa de "busca da literatura", segundo o referido modelo.

Quadro 1. Detalhes da busca de literatura.

\begin{tabular}{|l|l|}
\hline \multicolumn{1}{|c|}{ Busca da literatura } \\
\hline $\begin{array}{l}\text { Estratégia de busca: bases de } \\
\text { dados, palavras-chave }\end{array}$ & $\begin{array}{l}\text { Bases de dados: Scielo, Web of Science e Biblioteca Virtual Pearson } \\
\text { Metabuscadores: Portal de Periódicos da CAPES e Google Scholar } \\
\text { Palavras-chave: "políticas públicas", "políticas públicas indígenas", "direitos indígenas", "dominação } \\
\text { estatal", "inclusão/exclusão indígena", "comunidades tradicionais" e "Estado e comunidade indígena" }\end{array}$ \\
\hline $\begin{array}{l}\text { Critérios de } \\
\text { inclusão/exclusão: tipos de } \\
\text { estudos, idiomas, período de } \\
\text { tempo, etc. }\end{array}$ & $\begin{array}{l}\text { Período de tempo especificado: 1910 - pós criação do SPLINT (Serviço de Proteção aos Índios e } \\
\text { Localização dos Trabalhadores Nacionais) }\end{array}$ \\
$\begin{array}{l}\text { Idiomas: português, inglês e espanhol } \\
\text { agências multilaterais e bases de dados estatísticas, como as do Instituto Brasileiro de Geografia } \\
\text { Estatística (IBGE) }\end{array}$ \\
$\begin{array}{l}\text { Critérios de inclusão/exclusão: } \\
\text { - leitura de título, resumo e palavras-chave } \\
\text { - leitura da introdução e conclusão } \\
\text { - leitura completa do documento } \\
\text { A cada estágio de leitura foi realizado o cotejamento com os objetivos específicos da pesquisa }\end{array}$ \\
\hline $\begin{array}{l}\text { Disponibilidade dos estudos } \\
\text { selecionados }\end{array}$ & \begin{tabular}{l} 
Documentos de acesso aberto \\
\hline
\end{tabular} \\
\hline
\end{tabular}

Fonte: Autores. 
É importante salientar que a leitura crítica das literaturas obtidas na busca foi realizada em cotejamento com o objetivo geral e com os objetivos específicos da pesquisa. Dessa forma, segundo a classificação de revisões de literatura tradicionais de Jesson, Matheson e Lacey (2011), obteve-se tanto uma revisão conceitual dos elementos pesquisados em tais objetivos como uma revisão de escopo, que aponta para agendas futuras de pesquisa na convergência de tais elementos.

\section{Resultados e Discussão}

\subsection{Políticas públicas e a realidade dos povos indígenas}

\subsubsection{Políticas públicas: ciclos de gestão}

As políticas públicas surgiram no início dos anos de 1950 e se desenvolveram como área de conhecimento, a princípio, nos Estados Unidos. Ao longo dos anos, os estudos sobre o tema tomaram proporções maiores e se expandiram, chegando ao Brasil. Nos estudos das políticas públicas são desenvolvidos variados temas, os quais podem se alterar, de acordo com o interesse da sociedade, padrão de vida, mudanças tecnológicas, compreensão de bem comum, entre outros. No entanto, para a criação de uma política pública, há várias decisões que devem ser levadas em conta (Brasil \& Capella, 2016, Mello, 2018).

Segundo Secchi (2013), há diferentes classificações e explicações para a compreensão de como são criadas as políticas públicas. No entanto, há certa conformidade em se tratando das divisões do processo de elaboração dessas políticas, as quais podem ser observadas na Figura 1 .

Figura 1. Fluxo da criação de políticas públicas.

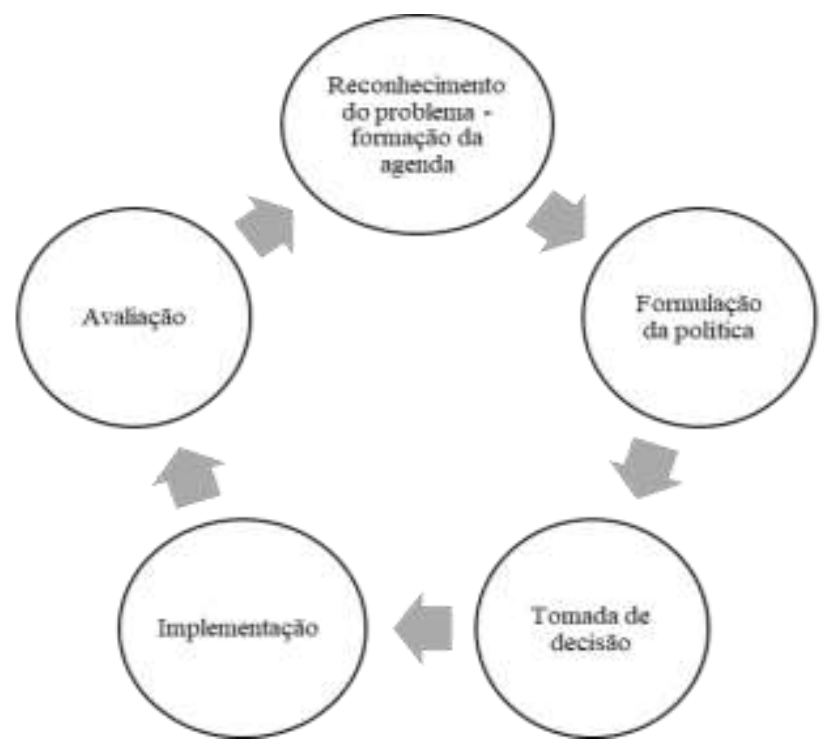

Fonte: Autores, com base em Mello (2018).

Como apresentado na Figura 1, a primeira etapa é caracterizada pela formação da agenda de políticas públicas. Tal agenda consiste em uma lista de prioridades que são inicialmente estabelecidas. Portanto, nesta fase, os atores devem dedicar intensamente suas energias e atenções, pois é a partir da agenda que se extraem os conjuntos de temas que serão efetivamente tratados como possível objeto de política pública. Essa fase é primordial, pois, por meio dela é que serão realizados a avaliação 
de custo-benefício, o estudo do cenário, a urgência do problema, a necessidade política e os recursos disponíveis. Todavia, estar na agenda não significa que tal problema será resolvido (Rua, 2014, Agum, Riscado \& Menezes, 2015).

Para a agenda ser elaborada, há atores que fazem parte de sua definição e podem ser considerados atores estatais ou sociais, os quais operam em níveis subnacionais, nacionais e internacionais. Os atores estatais estão inseridos na categoria de atores governamentais, sendo eles: políticos, designados politicamente, burocratas e juízes. Já os atores sociais são representados pela categoria de atores não governamentais, como os grupos de interesses, partidos políticos, meios de comunicação, destinatários de políticas públicas e organizações do terceiro setor (Souza et al., 2017).

Contudo, os atores-chave são do Estado, dado que têm autoridade legal de abordar temas que chamem a atenção do governo, portanto, desempenham papel fundamental na definição da agenda. Apesar disso, os atores sociais apresentam o maior contingente na idealização de política pública, podendo se unir por um objetivo em comum. Observa-se que, quanto maior o interesse em um mesmo problema, maior será a possibilidade de elaboração de políticas públicas para a resolução desse (Wu et al., 2014).

A segunda etapa do ciclo de políticas públicas é a formulação da política. Esta fase é dedicada a gerar opções sobre o que fazer em relação ao problema público. "Sendo assim, enquanto a fase de definição da agenda no ciclo da política pública é essencialmente dedicada à identificação de 'para onde ir', a fase de formulação versa sobre 'como chegar lá"” (Matos et al., 2019, p. 18).

A formulação das políticas públicas se traduz no estabelecimento das normas que permitirão sua implementação pelos diversos atores envolvidos, para isso, é estudado o aperfeiçoamento das políticas, a melhor alocação de recursos e a melhoria da qualidade de gastos. Portanto, essa fase impede que, posteriormente, ocorram erros na elaboração das políticas, os quais podem ser antecipadamente identificados e suprimidos. Sendo assim, é necessário que essas normas apresentem requisitos de clareza e precisão, para que possam alcançar os objetivos almejados (Secchi, 2013, Matos et al., 2019).

No entanto, é nesta fase que os diversos atores entram em conflito, pois cada um deles possui interesses que podem lhes beneficiar. Sendo assim, cada ator apresenta recursos de poder como: capacidade de afetar o funcionamento do sistema, meios de convencimento, influência, votos, entre outros, ou seja, por mais apropriada que seja a formulação técnica de uma alternativa, a decisão sempre envolve relações de poder, logo, significando que não existem soluções perfeitas (Rua, 1998).

Após a formulação da política, ocorre a terceira fase, a tomada de decisão. Para Santos et al. (2011), nesta fase, os interesses dos atores são analisados e os objetivos e métodos da política são evidenciados. Neste momento, os tomadores de decisão têm o problema definido e começam a buscar possíveis soluções. A respeito das decisões, elas implicam na consideração dos valores e interesses (econômicos, culturais, religiosos, éticos, políticos, entre outros), sendo assim, a tomada de decisão é considerada um processo multidimensional e interdisciplinar (Santos, 2016).

Entretanto, para Rua (1998), a tomada de decisão representa várias intenções sobre a resolução de um problema e nada garante que a decisão possa se transformar em ação, ou seja, não existe uma conexão ou relação direta entre o fato de uma decisão ter sido aceita e sua implementação. Segundo a autora, o que garante a modificação de uma decisão em ação é a efetiva resolução de todos os conflitos entrelaçados naquela política pública e, como essa solução é difícil de ser alcançada, considerase que foi tomada uma "boa decisão" quando os atores relevantes saem ganhando alguma coisa e quando nenhum envolvido acredite que saiu inteiramente prejudicado.

Depois de realizada a etapa da tomada de decisão, inicia-se a quarta fase, de implementação. De acordo com os autores Silva e Melo (2000, p. 4) "[...] a implementação corresponde à execução de atividades que permitem que ações sejam implementadas com vistas à obtenção de metas definidas no processo de formulação de políticas públicas". Para que essa fase ocorra como esperado, é importante que a execução de atividades apresente metas e objetivos bem definidos. A 
implementação, portanto, analisa os eventos e atividades que ocorreram após a decisão das diretrizes de uma política (Viana, 1996, Rua, 2014).

É este o momento de fazer a política sair do papel e funcionar efetivamente, envolvendo os vários aspectos do segmento administrativo como "[...] provisão de recursos no orçamento, formação de equipes, elaboração de minutas de projeto de lei autorizando a realização de concurso para contratação de servidores, elaboração de editais para aquisição de bens ou contratação de serviços" (Rua, 2014, p. 90). É importante que os atores envolvidos acompanhem a fase de implementação e que durante ela continuem sendo tomadas decisões, pois o desenho da política pode sofrer adaptações, isto é, mudanças incrementais que geram melhorias e levam as políticas a serem bem executadas (Rocha, 2012).

Contudo, a fase de implementação, mesmo sendo uma das mais importantes, nem sempre é efetivada conforme o planejado. Há várias políticas públicas que não conseguem sair do papel, e isso ocorre devido alguns fatores: a ausência de apoio burocrático e político para a implementação; a falta de clareza na definição das metas; a carência de capacidade operacional; poucos ou insuficientes recursos financeiros ou humanos, entre outros problemas. Com isso, a implementação passa a ser encarada como um conjunto de processos dinâmicos, suscetíveis às inseguranças e às mudanças, podendo, então, distanciar a implementação dos propósitos pela qual foi formulada (Wu et al., 2014, Tenório \& Santos, 2018).

A última fase do ciclo de políticas públicas é a avaliação, na qual são avaliados tanto os meios utilizados como os objetivos atingidos pela política. A avaliação pode ser realizada em todas as etapas das políticas públicas, gerando uma maximização dos resultados conquistados com os recursos que foram designados. Portanto, o processo de avaliação analisa os impactos e as ações cumpridas pelas políticas e, conjuntamente, busca verificar a eficiência, a eficácia e a efetividade da política implementada (Lopes, Amaral \& Caldas, 2008).

Santos (2016) aponta que a eficiência está relacionada com o rendimento que a política apresentou, ou seja, a alocação de recursos e os resultados obtidos; a eficácia, por sua vez, diz respeito à satisfação sob a ótica do público-alvo, o qual analisa se a política resolveu ou não o problema; a efetividade refere-se ao alcance das metas estipuladas pela visão dos formuladores dos objetivos da política. Os resultados apresentados por uma avaliação podem gerar três situações, sendo elas i) ajudar no aperfeiçoamento da política para sua continuação, ii) acabar com a política presente ou iii) criar uma nova política. Além disso, a avaliação é uma ferramenta política e os resultados dela podem ser usados para melhorar programas, agendas de políticas públicas e prestar contas aos cidadãos (Serafim \& Dias, 2012).

É importante ressaltar que o ciclo das políticas públicas é uma visão teórica sobre a criação de uma política. No mundo real das políticas públicas, há um infindável conjunto de interesses. Com isso, os modelos conceituais, muitas vezes, são incabíveis ou incapazes de se adaptar às arenas, instituições, marcos legais, atores envolvidos, culturas e marcos conceituais, de modo que é necessário um olhar crítico sobre os temas, as condições nacionais e as realidades pontuais que serão analisados (Fonseca, 2013).

\subsubsection{Políticas públicas no âmbito das comunidades indígenas}

A história é testemunha das diversas tragédias impostas pelos colonizadores aos indígenas, como escravidão, massacres, genocídios, guerras, etnocídios, entre outras crueldades que dizimaram e colaboraram com a diminuição dos povos indígenas até os dias atuais. Alguns dos fatores que cooperaram para o processo de dominação e extermínio dos indígenas brasileiros foi a manipulação que os portugueses usaram para gerar desentendimentos internos entre diferentes grupos étnicos, seja provocando brigas entre tais grupos ou os usando para aumentar seus exércitos e, assim, atacarem grupos adversários (Luciano, 2006).

De acordo com o mesmo autor, após essas trágicas experiências, os indígenas se uniram para lutar por seus direitos.

Foi então que começaram a surgir organizações representativas internacionais e nacionais, a partir da década de 1970, as quais 
hoje são denominadas como movimento indígena organizado. Tal movimento representa o esforço conjunto de lideranças, povos e organizações indígenas que têm como objetivo lutar pela terra, saúde, educação e por outros direitos. Com a organização do movimento indígena, foi possível sensibilizar a sociedade brasileira a Assembleia Nacional Constituinte a aprovar, em 1998, os direitos indígenas na Constituição Federal (Luciano, 2006).

No entanto, como observou Shiraishi Neto (2007, p. 135), “[...] em muitas partes do mundo esses povos não podem gozar dos direitos humanos fundamentais na mesmo [sic] medida que o restante da população dos estados em que vivem, e que suas leis, valores, costumes e perspectivas vêm em geral se deteriorando". Com isso, foram criados instrumentos internacionais que visam à adoção de normas de caráter coletivo, dedicadas exclusivamente aos direitos dos povos indígenas (Salazar, 2018).

Um dos principais instrumentos criados sobre os direitos dos povos indígenas foi a Convenção $n^{\circ} 169$ da Organização Internacional do Trabalho (OIT), em 07 de junho de 1989, chamada de Convenção OIT sobre Povos Indígenas e Tribais em Países Independentes. Esta convenção estabelece direitos e princípios básicos para os povos indígenas, entre os quais: i) direito ao respeito a sua integridade, instituições e culturas; ii) direito à propriedade e à posse sobre terras que ocupam; iii) princípio da não-discriminação; iv) direito de determinar suas próprias formas de desenvolvimento; v) direito de participar diretamente da tomada de decisão sobre programas e políticas que os afetem; e vi) direito de serem consultados sobre assuntos administrativos ou legislativos que possam lhes afetar. Tudo o que está previsto na Convenção $\mathrm{n}^{\circ} 169$ é de cumprimento obrigatório para os países que a ratificam - consentimento em obrigar-se a um acordo. Ou seja, os Estados devem adaptar a legislação nacional para poderem desenvolver a convenção em seus países, além de revogar todas as normas que são a ela opostas (Salazar, 2018).

Diante disso, é notável o dever Estado de propiciar políticas públicas diferenciadas às comunidades indígenas, as quais sejam adaptadas à multiplicidade de identidades culturais. Em outras palavras, devem ser levados em consideração o contexto cultural que os indígenas estão inseridos, devendo esses ser encarados como sujeitos de direitos, com identidade e capazes (Schwingel, 2002). Nesse sentido, Holanda (2015) afirma que devem ser consideradas as práticas históricas desses povos assim como deve haver espaços para opinarem e participarem do processo de desenvolvimento das políticas, para que, assim, sejam garantidos seus direitos econômicos, culturais, sociais, ambientais, etc.

Diferentemente das políticas criadas para os não indígenas, quando as políticas públicas são voltadas aos povos indígenas, há algumas dificuldades encontradas nas fases que foram anteriormente analisadas. A primeira dificuldade, e a mais frequente, é o direito de participar das tomadas de decisões relacionadas aos assuntos que os afetam diretamente. Muitas das políticas públicas, nomeadas como específicas e diferenciadas, acabam sendo realizadas com pouca autonomia e protagonismo indígena, o que é, de fato, contraditório, visto que a participação do beneficiário na política específica para esse é fundamental (Silva \& Kuhn Junior, 2018). Nesse sentido, é de extrema importância que exista espaço para a participação dos indígenas nas políticas públicas a eles direcionadas, pois, somente assim será assegurada eficácia e melhorias para essa população (Guirau \& Silva, 2013). Entende-se como participação, a compreensão de eficiência - melhores resultados e o empoderamento - poder ou capacidade de um indivíduo ou comunidade em obter melhores condições de vida, o que direciona a escolha de lideranças capazes e responsáveis em comunicar os interesses como a busca pelo desenvolvimento do coletivo que representa (Ayala \& Fehlauer, 2005; Souza et al., 2021).

Para os indígenas, quando ocorre a participação na tomada de decisões relativas aos assuntos que os envolvem, isso é entendido como uma conquista. De acordo com a Declaração das Nações Unidas sobre os direitos dos povos indígenas (2006, p. 20) essa participação "[...] tem um impacto direto sobre o gozo efetivo de outros direitos humanos, como a livre determinação, a igualdade, a integridade cultural, o consentimento livre, prévio e informado e o direito à propriedade".

No Brasil, até recentemente, as políticas indigenistas eram realizadas quase que exclusivamente pelos órgãos federais. No entanto, atores exclusivamente não indígenas não possuem a expertise para trabalhar com povos indígenas, pois não 
conhecem a realidade dessas comunidades por completo e, frequentemente, acabam por criar programas governamentais que não se encaixam nos padrões socioculturais comunitários. No entanto, a partir da década de 1990, com a Constituição Federal, houve a construção da relação entre o Estado brasileiro e os povos indígenas de maneira participacionista e não integracionista. Sendo assim, a intervenção e a negociação de lideranças indígenas tornaram possível que certas pautas de políticas públicas fossem analisadas. Com isso, as questões indigenistas passaram a ser colocadas na agenda de desenvolvimento do governo (Costa e Silva, 2013).

Entretanto, segundo a autora Costa e Silva (2013), mesmo com tais avanços, devido ao perfil social e político dos indígenas, estes ainda não têm conseguido se organizar como grupos de pressão eficientes. Isto é, não conseguem causar modificações nas instituições existentes por sempre estarem em desvantagem no desenho institucional. Outra dificuldade que pode ser observada, infelizmente, é que esses grupos conseguem alcançar as fases de implementação das políticas, mas não conseguem ter muito acesso aos processos de elaboração dessas. Tal situação implica, na prática, que não há inserção desse povo na realidade política do país, impossibilitando que eles possam conciliar os interesses da sociedade nacional com suas tradições e interesses (Bicalho et al., 2018).

Portanto, há necessidade do amadurecimento das políticas públicas, principalmente em se tratando de públicos diferenciados. Para a defesa de seus direitos, os povos indígenas devem ser consultados e inclusos nas etapas anteriores à implementação das políticas públicas. Logo, faz-se necessário o aprimoramento no modo que ocorre a comunicação entre os atores, a fim de legitimar os movimentos sociais indígenas, sua influência política e nas políticas públicas (Borges, 2016, Fernandes \& Uribe, 2019).

Embora a representação dos povos indígenas ainda não seja tão desenvolvida como seria necessário para que imprimam seus interesses, a autorrepresentação do movimento indígena no Brasil já vem se constituindo desde 1973 por ocasião da promulgação do Estatuto do Índio. O Estatuto estendeu a proteção das leis, nos mesmos termos em que se aplicam aos demais brasileiros, aos indígenas (Lei nº 6.001, 1973). Desde então, os movimentos sociais ganharam força. Contudo, até o momento presente, a Constituição Federal de 1988 continua sendo um dos marcos principais para o avanço dos direitos indígenas, pois reconhece a capacidade, organização social, costumes, línguas, crenças e tradições e os direitos originários sobre as terras (Constituição da República Federativa do Brasil, 1998).

No ano de 2006, outro ponto marcante na representação indígena foi a criação da Comissão Nacional de Política Indigenista - CNPI, cujo objetivo foi de propor diretrizes e prioridades para a política indigenista e o acompanhamento das ações relacionadas à temática indígena, por meio dessa comissão, foi estabelecido um canal de diálogo entre os órgãos governamentais responsáveis pela política indigenista e os representantes indígenas (Funai, 2021). A posteriori criou-se a Política Nacional de Desenvolvimento Sustentável dos Povos e Comunidades Tradicionais (PNPCT), a qual define povos e comunidades tradicionais e territórios tradicionais, em seu art. $3^{\circ}$, com a seguinte redação:

I - Povos e Comunidades Tradicionais: grupos culturalmente diferenciados e que se reconhecem como tais, que possuem formas próprias de organização social, que ocupam e usam territórios e recursos naturais como condição para sua reprodução cultural, social, religiosa, ancestral e econômica, utilizando conhecimentos, inovações e práticas gerados e transmitidos pela tradição;

II - Territórios Tradicionais: os espaços necessários à reprodução cultural, social e econômica dos povos e comunidades tradicionais, sejam eles utilizados de forma permanente ou temporária, observado, no que diz respeito aos povos indígenas e quilombolas, respectivamente, o que dispõem os arts. 231 da Constituição e 68 do Ato das Disposições Constitucionais Transitórias e demais regulamentações; (Decreto $\mathrm{n}^{\circ}$ 6.040, 2007).

A política tem o intuito de promover diversos direitos aos povos e comunidades tradicionais, entre eles, visibilidade, reconhecimento e valorização a respeito da diversidade, segurança alimentar e nutricional, acesso à informação e 
conhecimento, desenvolvimento sustentável, pluralidade socioambiental, consolidação e preservação dos direitos, por fim, a articulação com as demais políticas públicas (Decreto $\left.n^{\circ} 6.040,2007\right)$.

\subsection{Comunidades indígenas e a relação de dominação estatal}

\subsubsection{Comunidades indígenas: análises culturais, sociais e econômicas}

As comunidades tradicionais estão presentes em todo o mundo, cada uma com diferentes características. No Brasil, não seria diferente; o país apresenta uma grande diversidade de povoados com particularidades distintas, o que forma sua multiculturalidade. No que se refere à estruturação desses grupos, sua vivência sustenta-se na cultura, língua, tradições, valores e costumes (Costa, 2010). Além disso, ressalta-se também a importância do local onde são formadas as comunidades, cujos territórios compõem um espaço geográfico e humano no qual há relações informais (Moraes et al., 2017).

De modo muito expressivo, no território brasileiro, os povos indígenas são os povos originários mais antigos, sendo a primeira população a habitar o país, antes mesmo da colonização portuguesa, fato que ocorreu no século XV (Ramos, 2002). De acordo com o último censo realizado pelo IBGE, em 2010, identificou-se que a população indígena no Brasil é de 896 mil pessoas. Dessas pessoas, 572 mil, ou 63,8\%, viviam na área rural e 517 mil, ou 57,7\%, estão em Terras Indígenas oficialmente reconhecidas, como pode ser observado na Tabela 1 (IBGE, 2010).

Tabela 1. População indígena no Brasil por situação de domicílio rural ou urbano e por localização de domicílio - 2010.

\begin{tabular}{|c|c|c|c|}
\hline \multirow{2}{*}{ Localização do domicílio } & \multicolumn{3}{|c|}{ População indígena por situação do domicílio } \\
\cline { 2 - 4 } & Total & Urbana & Rural \\
\hline Total & 896.917 & 324.834 & 572.083 \\
\hline Terras Indígenas & 517.383 & 325.963 & 491.420 \\
\hline Fora de Terras Indígenas & 379.534 & 298.871 & 80.663 \\
\hline
\end{tabular}

Fonte: IBGE (2010).

Quando os números são desagregados por regiões, verifica-se que a região Norte apresenta grande expressividade no quantitativo da população indígena. Corroborando esta informação, observa-se que a região Norte concentra a maior parte das Terras Indígenas em âmbito nacional. De acordo com o último Censo Agropecuário, realizado em 2017, identificou-se que as Terras Indígenas somam 117,639 milhões de hectares, conforme apresentado na Tabela 2 (IBGE, 2017).

Tabela 2. População indígena no Brasil segundo grandes regiões e por localização de domicílio - 2010.

\begin{tabular}{|c|c|c|c|c|}
\hline \multirow{2}{*}{ Regiões } & \multicolumn{3}{|c|}{ População indígena por situação do domicílio } \\
\cline { 2 - 5 } & \multirow{2}{*}{ Total } & Lerras Indígenas & $\begin{array}{c}\text { Fora de Terras } \\
\text { Indígenas }\end{array}$ & $\begin{array}{c}\text { Percentual } \\
\text { nas Terras } \\
\text { Indígenas (\%) }\end{array}$ \\
\cline { 2 - 5 } & 342.836 & 251.891 & 90.945 & 73.5 \\
\hline Norte & 232.739 & 106.142 & 126.597 & 45.6 \\
\hline Nordeste & 99.137 & 15.904 & 83.233 & 16.0 \\
\hline Sudeste & 78.773 & 39.427 & 39.346 & 50.1 \\
\hline Sul & 143.432 & 104.019 & 39.413 & 72.5 \\
\hline Centro-Oeste & 896.917 & 517.383 & 379.534 & 57.7 \\
\hline Brasil & & & \\
\hline
\end{tabular}

Fonte: IBGE (2017). 
No entanto, é importante que se conheçam as dinâmicas que produziram as atuais estatísticas durante o longo e contínuo processo de colonização sobre os povos indígenas, o qual afetou e afeta profundamente as questões históricas, sociais, econômicas, culturais, ambientais e todas as demais dimensões da sociabilidade indígena.

O primeiro contato entre os indígenas e não indígenas aconteceu no instante em que os portugueses desembarcaram no território brasileiro, em 1500. De imediato, observou-se que o país já tinha dono, os Tupinambás, Tukanos, Jê, Guaranis, Aruak, Karib, Tapuias, Panos e Charruas, os quais foram descritos para o rei de Portugal por meio das cartas escritas por Pero Vaz de Caminha (Nimuendajú, 2017). Nessas cartas, ressaltava-se o interesse dos portugueses pelas exuberantes riquezas brasileiras, principalmente, pelo pau-brasil, ouros e mão de obra indígena. Pero Vaz de Caminha descreveu a população indígena como "[...] pardos, todos nus, sem coisa alguma que lhes cobrisse suas vergonhas. Nas mãos traziam arcos com suas setas". (Caminha, 1500).

Constatou-se que a nudez não trazia conotação sexual para os indígenas. Para eles, adornos, trajes e pinturas corporais eram utilizados em ocasiões especiais, ritos, comemorações e festas, costumes os quais eram realidade em diferentes tribos e são válidos até hoje. Os hábitos mais conhecidos são pintura no corpo, utilização de adornos feitos por eles mesmos, tais como, colares, pulseiras, brincos, tornozeleiras e cocares. Outro costume é a música e a dança, ora para festejar, expressando alegria, ora para dançar, amenizando o sofrimento (Ramos, 2002, Andrade \& Silva, 2017).

As vestimentas utilizadas para cobrirem as partes íntimas foram introduzidas pelos portugueses. Esse costume foi adotado pelos povos indígenas à medida que aumentaram o contato com a sociedade (civilização) - sofrendo o processo de aculturação. Por apresentar um clima tropical e por habitar nas matas, a utilização de roupas não era interessante para os indígenas. Quando usam roupas, são tangas ou saiotes de plumas e penas, para cobrir apenas as partes intimas. As camisetas e calças são utilizadas apenas quando ocorre o contato com não indígenas (Lima, 2016).

A mesma autora destaca que os indígenas praticam o nomadismo e se alimentam da caça e pesca, vivendo em aldeias, comandadas pelo pajé. São nestas aldeias onde os indígenas desenvolvem os trabalhos de artesanato, produzem alimentos (hortas) e artefatos, tanto para a caça como para os combates (canoas, arco, flecha, armadilhas). As técnicas e macetes utilizados na fabricação são passados de geração a geração (Lima, 2016).

Considerando o processo de levar os costumes para as gerações futuras, deve-se incluir a necessidade da cultura organizacional na tribo. A cultura pode ser definida como "[...] um conjunto complexo que inclui conhecimento, crença, arte, moral, lei, costumes e várias outras aptidões e hábitos adquiridos pelo homem como membro de uma sociedade" (Mello, 2001, p. 40), a organização é caracterizada pelo trabalho coletivo, em que ocorre à divisão das tarefas, estabelecendo as funções de cada integrante do grupo.

Quanto a tais funções, o pajé é o indígena de maior influência numa comunidade indígena, possuindo amplo conhecimento sobre a cultura e a religião da terra indígena. Ele tem a responsabilidade de sustentar as tradições, passando-as para os curumins - indígenas mais jovens. Os curumins do povoado assumem funções distintas; homens são responsáveis por fabricar as ocas e instrumentos utilizados para a pesca e caça, além de caçar o alimento e proteger a tribo nas guerras; as mulheres são responsáveis por cuidar dos filhos, das hortas, trabalhar com a cerâmica e os artesanatos, tanto para uso próprio, quanto para o comércio (Luciano, 2006). Com a produção e o cultivo, as mulheres movimentam a economia das aldeias, vendendo suas artes e alimentos. Essa comercialização ocorre por meio da globalização que, segundo Silva (2009), é capaz de modificar e inovar a identidade de um indivíduo. Já o cacique é o líder político e administrativo da aldeia, o qual deve conservar a ordem e o bom andamento da tribo (Luciano, 2006).

Além dos traços culturais próprios, alguns traços da cultura indígena passaram a fazer parte da cultura e/ou da memória brasileira no geral. Nesse sentido, Costa (1943, p. 15) afirma que "Tão forte foi sempre a influência da língua indígena sobre a vida brasileira, que os bandeirantes não fugiram a dar aos lugares que descobriram nomes de procedência 
tupi". Muitas cidades, escolas, centros comerciais, ruas, etc., apresentam os nomes de indígenas, suas tribos e seus deuses. Esta é uma forma da sociedade não indígena homenagear e tributar os que aqui viveram e vivem. A exemplo de tal feito, tem-se a cidade de Tupã, cujos nomes das ruas, escola, museu, bairros e da própria cidade têm referência indígena, uma vez que, antigamente, diversas etnias habitavam a região, entre as principais estão os povos Kaingang, Krenak, Terena, Pankararu, Fruiô e Atikun, os quais, atualmente, formam a Aldeia Vanuíre. Muitos dos indígenas foram desterrados dos seus territórios e transferidos para a aldeia, como os Kaingangs, que eram originários da região e estão também presentes no norte e noroeste do Rio Grande do Sul. Os Krenaks, por sua vez, vieram de Minas Gerais (Vicente et al., 2017, Rodrigues et al., 2018).

Em contraponto com o objetivo de manter a memória indigenista cada vez mais viva, observou-se com o passar do tempo, desde o primeiro contato com os não indígenas, a dizimação destes povos. Desde 1500 até 1970 a população indígena brasileira decresceu e muitos povos foram extintos - estiava-se a presença de 3 milhões de indígenas no início do período colonial, número que diminui para aproximadamente 70 mil em 1970. Um exemplo da violência sofrida aconteceu no governo de Mem de Sá, no Recôncavo Baiano, em 1558, o Governador Geral do Brasil foi responsável pela morte de 30 mil Tupinambás (Gomes, 1988). No entanto, nas últimas décadas, este cenário se modificou. Em 2010, havia uma população de cerca de 800 mil indígenas no país. Vale ressaltar que os povos indígenas somente foram incluídos no censo demográfico a partir de 1990 (IBGE, 2010).

Tal decréscimo na população dos povos indígenas se deu em consequência de vários fatores genocidas ${ }^{1}$ e etnocidas ${ }^{2}$, com o objetivo de exterminá-los e afastá-los dos territórios desejados pelos colonizadores, os quais não haviam conseguido escravizá-los para se apropriar de suas terras e riquezas (Dantas, 2011). A cultura, a sociedade e a economia dos povos indígenas, em sua maior parte, encontra-se hoje alterada pela fricção cultural com os não indígenas. No entanto, além dos massacres cometidos contra os povos indígenas, houve há introdução de doenças infecciosas como sarampo, gripe e varíola que contribuíram para a dizimação dos índios no Brasil (Coimbra Jr, Santos \& Escobar, 2005, Souza et al., 2020). Segundo a Portaria do Ministério da Saúde n 254 (2002), tais doenças foram ocasionadas, principalmente, pelas condições de vida que os indígenas eram submetidos, tal como trabalho forçado, maus tratos, confinamento e escravidão.

\subsubsection{Relação de dominação estatal}

Em se tratando das relações do Estado e sociedade, é importante trazer a conceituação de poder e dominação. Segundo Max Weber, "[...] poder significa toda probabilidade de impor a própria vontade numa relação social, mesmo contra resistências, seja qual for o fundamento dessa probabilidade" (Weber, 2009, p. 33). Ou seja, poder é exercido de uma pessoa ou grupo sobre outras partes da sociedade.

Elenca-se a este conceito a dominação que, de acordo com Weber (2008), diz respeito à expectativa de se conseguir a obediência em uma ordem (mandato) numa relação que necessita sempre ao menos dois sujeitos, o dominador (dá à ordem e espera a obediência) e o dominado (obedece ao mando). Quando se trata da comunidade indígena, o Estado é o dominador e os indígenas são os dominados. Dentre os tipos de dominação, existem duas formas, a dominação ilegítima e a legítima. A dominação ilegítima é um autoritarismo, estando ligado a uma imposição pura e simples. Ao contrário dessa, a dominação legítima é uma relação de mando para com alguém que aceita e dá o consenso sobre a autoridade (Weber, 2008).

\footnotetext{
${ }^{1}$ Crime de genocídio: Art. $1^{\circ}$ Quem, com a intenção de destruir, no todo ou em parte, grupo nacional, étnico, racial ou religioso, como tal:

a) matar membros do grupo;

b) causar lesão grave à integridade física ou mental de membros do grupo;

c) submeter intencionalmente o grupo a condições de existência capazes de ocasionar-lhe a destruição

física total ou parcial;

d) adotar medidas destinadas a impedir os nascimentos no seio do grupo;

e) efetuar a transferência forçada de crianças do grupo para outro grupo; (Lei no $2.889,1956)$.

2 '[...] destruição sistemática dos modos de vida e pensamento de povos diferentes daqueles que empreendem essa destruição. Em suma, o genocídio assassina os povos em seu corpo, o etnocídio os mata em seu espírito (Clastres, 2004, p. 56).
} 
Weber (2001) dividiu a dominação legítima em três classificações: legal, tradicional e carismática. A primeira, dominação legal, é o poder existente nas organizações e também descreve as relações de poder mais particulares entre o Estado e as comunidades indígenas (presidente e cidadãos); a segunda, a dominação tradicional, é o poder que decorre das tradições, como a gerontocracia e o patriarcalismo (cacique e aldeões); a terceira, a dominação carismática, é o poder decorrente da personalidade de um líder e sua capacidade de mobilizar pessoas (Jesus Cristo e cristãos).

A dominação sobre os povos indígenas começou no período colonial e ocorre até os dias atuais. No entanto, ela parece ser muito mais perniciosa atualmente, pois está nas sutilezas econômicas e políticas, o que gerou e ainda gera múltiplos conflitos de etnicidade. A partir do século XXI, o Estado entrou na disputa com outros dominadores com o intuito de dominar os povos indígenas, entre eles fazendeiros, religiosos, militares, garimpeiros, etc. (Santos, 2012). Ressalta-se que esses atores agem de acordo com interesses socioeconômicos e benefícios próprios, sem pensar nos valores e costumes indígenas, dado que almejam conquistar espaços e/ou territórios desses (Souza Filho \& Bergold, 2013).

O Estado trabalha como estrutura de dominação de uma classe social pela outra, de modo que a classe dominante se sobrepõe a classe dominada, que, por sua vez, possui dominação sobre outra classe e assim sucessivamente (Bittar \& Almeida, 2008). Nesse sentido, “[...] o Estado seria também uma instituição a serviço da classe dominante, pois, além de se estruturar por um modelo jurídico, é fonte criadora do Direito" (Nader, 2019, p. 229).

Segundo Ferreira (2007), o Estado possui ainda mais dominação sobre os indígenas, pois os considerava como crianças, com a ressalva de que eram considerados abaixo das crianças civilizadas que vivem na sociedade, uma vez que os indígenas são foram por muito tempo considerados primitivos, por isso, sendo classificados também como incapazes. Ainda sobre o papel do Estado, Ferreira (2007, p. 9) afirma que

O papel político, a ação e pensamento indígenas são obliterados, colocados como meramente determinados pela sociedade nacional e pelo Estado-Protetor. No fim, o Estado aparece como o verdadeiro e único sujeito da história indígena, já que - sendo o índio incapaz, este somente existe graças ao Estado. Assim a relação e o regime tutelar, aparecem como único meio possível de impedir o extermínio final e definitivo dos índios. O índio não existe sem a tutela.

Ferreira (2007) afirma que o Estado e o regime tutelar impõem forças maiores sobre os indígenas, os quais se tornam vinculados e muitas vezes dependentes do Estado, que formula e implementa políticas públicas destinadas a esse grupo, a fim de garantir sua sobrevivência na sociedade brasileira.

A principal forma de dominação sobre os indígenas ocorre quando não há espaço para a participação desses na política, ou quando há a descredibilização ou criminalização dos movimentos e manifestações dos indígenas, com políticas contraditórias aos direitos assegurados a estes povos na constituição, como é o caso da demarcação das Terras Indígenas (Cohn, 2001).

\subsection{Estado e comunidade indígena}

\subsubsection{Transformações dos direitos indígenas ou políticas públicas indigenistas}

Os indígenas necessitam de políticas diferenciadas, visto que possuem culturas, costumes e tradições divergentes das pessoas não indígenas. Tais políticas são discutidas no âmbito educacional, territorial, de assistência social e saúde. De acordo com Rangel (2013), o conceito de política pública indigenista ganhou notoriedade após o I Congresso Indigenista Interamericano, realizado no México em 1940, em que foram estabelecidos metas e princípios com o intuito de propor alterações das políticas para as populações indígenas. 
No contexto brasileiro, desde o século XVI, existiram instrumentos legais que definiam e indicavam políticas públicas para os indígenas, com relação principalmente a legitimação de seus diretos e a soberania de seus territórios. Como recorte temporal, buscou-se analisar os instrumentos a partir de 1910, justifica-se a delimitação temporal, por meio da criação do Serviço de Proteção ao Índio e Localização de Trabalhadores Nacionais (SPLINT), pelo Decreto 8.072, que posteriormente recebeu como nomenclatura Serviço de Proteção aos Índios (SPI), a qual foi substituída pela Fundação Nacional do Índio (FUNAI) mais tarde. Além desses instrumentos, foi criado também o Estatuto do Índio (Rangel, 2013, Lopes, 2014). Esses e outros principais marcos para esses povos são apresentados na Figura 2.

Figura 2. Linha do tempo dos principais marcos legais indígenas.

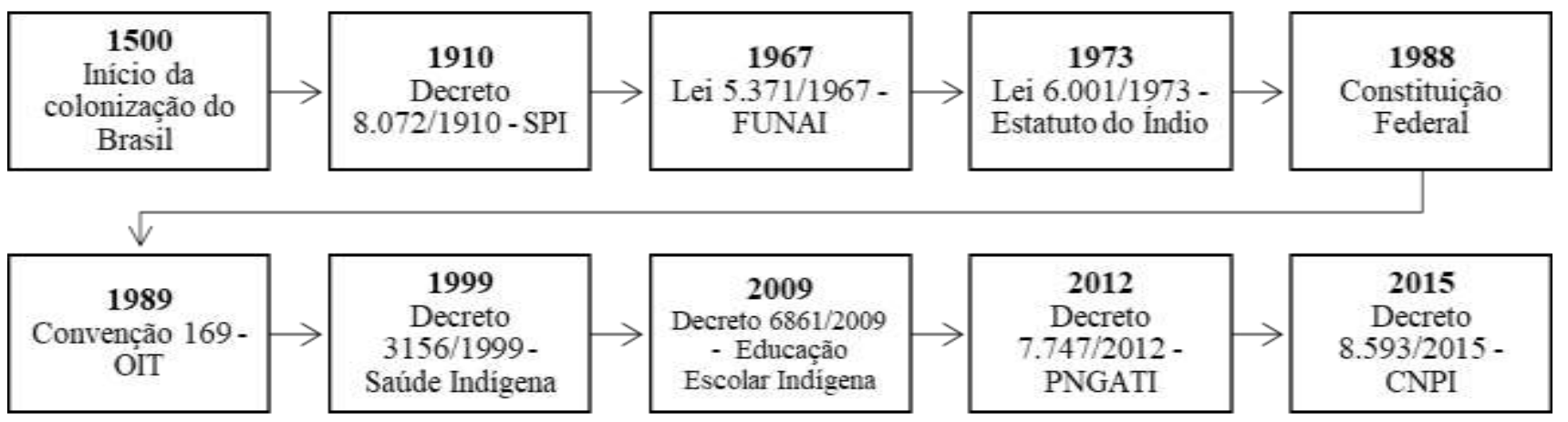

Fontes: Autores, com base em Decreto $n^{\circ} 3.156$ (1999), Decreto $n^{\circ} 5.051$ (2004), Decreto $n^{\circ} 6.861$ (2009), Decreto $n^{\circ} 7.747$ (2012), Rangel (2013), Lopes (2014) e Decreto $n^{\circ} 8593$ (2015).

O SPI tinha como objetivo afastar a catequização dos indígenas, que era realizada pela Igreja Católica, assegurandolhes o respeito, de acordo com suas línguas, crenças e modos de vida. Tinha como dirigente Cândido Mariano da Silva Rondon, conhecido por sua relação pacífica com os indígenas. Contudo, o SPI entrou em decadência administrativa em torno de 1957, por conta de denúncias de corrupção e abusos, assim, houve a extinção do órgão. No ano de 1967, houve a criação da FUNAI, que tem como atribuição a regularização fundiária, gestão ambiental e territorial das Terras Indígenas, bem como a defesa dos direitos desses. Em 1973, houve a aprovação do Estatuto do Índio, Lei n 6.001 , de 19 de dezembro de 1973 , que regulamenta a situação jurídica dos indígenas (Rangel, 2013, Lopes, 2014, Silva, 2017).

No final da década de 1980, os direitos indígenas foram reconhecidos, tendo os direitos territoriais, civis e políticos reafirmados pela Constituição Federal de 1988 (CF/88). Esses direitos compreendiam os indígenas como povos culturalmente diferenciados, por isso, passam a ter direitos sobre a terra, educação, saúde, e a cultura. A CF/88 é orientada pelo reconhecimento e fortalecimento dos diversos povos indígenas e para as legislações indigenistas futuras, as quais foram se desenvolvendo, destacando-se principalmente no contexto da saúde e da educação escolar (Borges, 2016, Silva, 2017, Lopes, 2017).

No ano de 1999 a saúde da população indígena no Brasil ganha destaque, pois é instituído, mediante Decreto n 3.156 , um Subsistema de Atenção à Saúde Indígena (SASI), vinculado ao Sistema Único de Saúde (SUS). De acordo com a Lei ${ }^{\circ}$ 9.836, é obrigatório observar a realidade local, a cultura dos indígenas e o melhor modelo a ser abordado para a atenção à saúde dos povos indígenas, além disso, a Lei estabelece as populações indígenas o direito a participar da formulação, acompanhamento e avaliação das políticas de saúdes (Brito et al., 2020, Lei nº 9.836, 1999).

Em 2004, por meio do Decreto 5.051, o Brasil se tornou signatário Convenção n 169 da Organização Internacional do Trabalho (OIT). Tal convenção é um instrumento internacional que trata sobre os povos indígenas e tribais em Estados 
Independentes, a qual aponta os principais avanços no reconhecimento dos direitos indígenas coletivos, especialmente nas dimensões econômicas, sociais e culturais (Decreto $\mathrm{n}^{\circ}$ 5.051, 2004).

De acordo com o Decreto n 6.861 (2009), a Educação Escolar Indígena (EEI) deve ser organizada com a presença dos povos indígenas, e levar em consideração as suas territorialidades, especificidades e necessidades. Alguns dos objetivos da EEI são a valorização das culturas indígenas, assim como, a preservação de suas diversidades étnicas, o fortalecimento da língua materna de cada comunidade, a elaboração e publicação de material didático especifico e diferenciado entre outros. A Educação Escolar Indígena é baseada na construção de conhecimentos universais e, todavia, carrega a valorização da identidade indígena, como os costumes, crenças, línguas e seus próprios processos educacionais (Mendonça \& Oliveira, 2020).

Em 2012, por meio do Decreto $n^{\circ}$ 7.747, criou-se a Política Nacional de Gestão Territorial e Ambiental de Terras Indígenas - PNGATI, cujo intuito é o de gerir o território, por meio da garantia e promoção, proteção, recuperação, conservação e utilização dos recursos naturais dispersos no meio ambiente em que a comunidade está estabelecida (Decreto ${ }^{\circ}$ 7.747, 2012). A política é sustentada por sete eixos: i.) proteção territorial e dos recursos naturais; ii.) governança e participação indígena; iii.) áreas protegidas, unidades de conservação e terras indígenas; iv.) prevenção e recuperação de danos ambientais; v.) uso sustentável de recursos naturais e iniciativas produtivas indígenas; vi.) propriedade intelectual e patrimônio genético e vii.) capacitação, formação, intercâmbio e educação ambiental (Decreto n ${ }^{\circ}$ 7.747, 2012). Para o desenvolvimento de políticas públicas destinadas aos povos indígenas, criou-se o Conselho Nacional de Política Indigenista - CNPI, o qual propõe, desenvolve, elabora e monitora as políticas públicas destinadas aos indígenas, revogando o decreto de 22 de março de 2006, o qual tratava da Comissão Nacional de Política Indigenista - CNPI, o que sustentou a criação do Conselho anos depois (Decreto $\mathrm{n}^{\mathrm{o}}$ 8.593, 2015). Precedendo o Conselho Nacional de Política Indigenista, aconteceu em 2016, a I Conferência Nacional de Política Indigenista - CNPI, a qual trata sobre previdência social e assistência social para os indígenas, com o objetivo de garantir os direitos individuais, autonomia e desenvolvimento. Nesta conferência foram discutidos assuntos como proteção territorial, participação social, direito à consulta, desenvolvimento sustentável, reafirmação da diversidade cultural e étnica do Brasil e direito à memória e à verdade (I Conferência Nacional de Política Indigenista, 2016, Souza et al., 2020).

\subsubsection{Outras políticas públicas indigenistas}

Em decorrência da invasão europeia em seu território, pode-se destacar a necessidade de políticas voltadas à territorialidade para os povos indígenas, dado que há ainda invasões em seus territórios, decorrente de ações, por exemplo, de garimpeiros, madeireiros, grileiros e fazendeiros. Além das invasões, os indígenas sofreram e sofrem com deslocamentos forçados, com a união de tribos e com a diminuição de seu espaço em decorrência de obras de infraestrutura (Borges, 2016).

Em concordância com a Declaração das Nações Unidas sobre os Direitos dos Povos Indígenas (2008, p. 14) “Os povos indígenas têm direito às terras, territórios e recursos que possuem e ocupam tradicionalmente ou que tenham de outra forma utilizado ou adquirido". Portanto, é necessário que as políticas públicas assegurem aos povos indígenas a preservação de suas culturas, condições para permanência em seus próprios territórios e a garantia de sobrevivência digna em seu espaço de vivência, permitindo que tenham controle de todas as atividades culturais, socioeconômicas e religiosas nas quais estão inseridos (Paula, 2008).

Para a defesa dos direitos sociais indígenas, existem os Centros de Referência em Assistência Social (CRAS), que são unidades públicas estatais da política de Assistência Social (AS), tendo como propósito proteger o grupo em questão de vulnerabilidades e riscos sociais em seus territórios. Um desses riscos são as aproximações de fazendas em torno das aldeias. Quando isto ocorre, os indígenas são transferidos para outras reservas sem antes serem consultados. O CRAS, por sua vez, movimenta-se para garantir o direito dos indígenas às terras, principalmente as que já lhes pertencem (Borges, 2016). Ainda de acordo com o autor, existem grandes demandas de informações para com o CRAS, que possui um número reduzido de 
funcionários, acarretando sobrecarga de tarefas, além de haver a falta de treinamento dos funcionários ao se relacionarem com as famílias de reservas indígenas (Borges, 2016).

É válido ressaltar também a ação dos Conselhos Tutelares, necessários devido à vulnerabilidade e ao risco social presente na aldeia. Contudo, as famílias indígenas temem a ação dos conselhos, pois as tomadas de decisões com menores de idades que possuem má conduta em função do consumo de álcool e drogas pode levar à retirada dos jovens indígenas de seu contexto familiar e os levar para fora da reserva, situação que ocorre sem diálogo com a comunidade (Borges, 2016).

Com relação a saúde, em 1999, foi editado o Decreto n ${ }^{\circ}$ 3.156, o qual dispõe sobre as condições para a prestação de assistência à saúde dos povos indígenas. O decreto estabeleceu a Política Nacional de Atenção à Saúde dos Povos Indígenas (PNASPI) que visa garantir aos povos indígenas o acesso à atenção integral à saúde, levando em conta os princípios e diretrizes do Sistema Único de Saúde (SUS), favorecendo a superação dos fatores que tornam essa população mais vulnerável, reconhecendo a eficácia de sua medicina e o direito desses povos à cultura própria (Portaria do Ministério da Saúde ${ }^{\circ} 254$, 2002). A política estabelece as seguintes diretrizes para orientar a definição de instrumentos de planejamento, implementação, avaliação e controle das ações de atenção à saúde dos povos indígenas:

i.) organização dos serviços de atenção à saúde dos povos indígenas na forma de Distritos Sanitários Especiais e Pólos-Base, no nível local, onde a atenção primária e os serviços de referência se situam;

ii.) preparação de recursos humanos para atuação em contexto intercultural;

iii.) monitoramento das ações de saúde dirigidas aos povos indígenas;

iv.) articulação dos sistemas tradicionais indígenas de saúde;

v.) promoção do uso adequado e racional de medicamentos;

vi.) promoção de ações específicas em situações especiais;

vii.) promoção da ética na pesquisa e nas ações de atenção à saúde envolvendo comunidades indígenas;

viii.) promoção de ambientes saudáveis e proteção da saúde indígena;

ix.) controle social (Portaria do Ministério da Saúde n 254, 2002).

Em 1999, criou-se também o Subsistema de Atenção à Saúde Indígena (SASI), por meio da Lei n 9.836, conhecida como Lei Arouca. O SASI é composto pelos Distritos Sanitários Especiais Indígenas (DSEIs) que se configuram em uma rede de serviços implantada nas Terras Indígenas para atender essa população, levando em conta critérios geográficos, demográficos e culturais. Considerando-se os aspectos de assistência à saúde, meio ambiente, habitação, saneamento básico, nutrição, educação sanitária, demarcação de terras e integração institucional, de acordo com os princípios do SUS (Lei $n^{\circ}$ 9.836, 1999; Moraes, 2018).

Cardoso (2014) aponta que o modelo médico assistencial para os indígenas se caracteriza como precário, mesmo em se tratando de ações básicas em saúde, e destaca a ausência de participação desses povos na formulação, planejamento, gestão e avaliação da política, o que deveria ocorrer por meio da representatividade nos Conselhos de Saúde (Cruz \& Coelho, 2012).

Cruz e Coelho (2012) apontam que os povos indígenas buscam a participação nas questões relativas às políticas indigenistas, principalmente as de saúde. Para a ocorrência do protagonismo indígena, há a necessidade da elaboração de estratégias que se pautam nas participações "autorizadas" e "não autorizadas". A participação "autorizada" diz respeito à participação indígena em reuniões dos Conselhos e Conferências de Saúde, reuniões com o Distrito Sanitário Especial Indígena (DSEI), elaboração e encaminhamento de cartas, bilhetes e abaixo-assinados para instituições responsáveis pela saúde indigenista, bem como ações, caso necessário, junto ao Ministério Público. Já a participação "não-autorizada" caracteriza ações como ocupação dos prédios, bloqueio de estradas, vicinais e ferrovias, retenção de veículos da saúde indigenista, denúncias nos meios de comunicação televisiva, escrita, on-line, ou até mesmo uma ameaça inicial de utilização das ações descritas inicialmente (Cruz \& Coelho, 2012). 
Logo, os povos indígenas buscam a autonomia e a garantia de seus direitos, utilizam de estratégias com a finalidade de reinvindicações referentes aos recursos financeiros para cursos de ação em termos saúde, participações nos conselhos e diversas participações com relação ao quadro de funcionários, operacionalização e gerenciamento das decisões tomadas na política indigenista (Cruz \& Coelho, 2012).

Sobre a educação para os indígenas, a CF/88 menciona que teriam direito ao ensino ministrado em língua portuguesa, porém, seria assegurado às comunidades a utilização de suas línguas maternas e aprendizados de sua própria cultura. Sendo assim, a Educação Escolar Indígena (EEI) consiste em oferecer subsídios que primam pela qualidade no ensino, mas, que preservassem as particularidades da cultura indigenista, portanto, a princípio, as políticas voltadas à educação apresentavam uma aprendizagem de inclusão de todos na sociedade (Fonseca \& Weigel, 2018).

Contudo, “[...] observa-se que a realidade da educação voltada para os povos indígenas é bem diferente daquilo que preconizam essas regulamentações e as normas legais. [...] e não segue um processo diferenciado de ensino de que os povos indígenas necessitam" (Pereira \& Brasileiro, 2016, p. 238). Alguns impasses observados são: os indígenas têm um modo particular de transmitir a educação por meio de suas culturas, para eles qualquer indivíduo adulto da comunidade pode ser um agente de educação, dispensando a figura de um professor; a educação não se limita a uma sala nem a um momento especifico, pois, para eles a educação é transmitida diariamente de forma coletiva; e, por fim, na maioria das escolas indígenas, utiliza-se da língua portuguesa, dificultando, assim, a preservação e a valorização da língua materna (Quaresma \& Ferreira, 2013, Souza \& Bruno, 2013).

Diante de todas essas políticas públicas destinadas às comunidades indígenas, observa-se que ainda faltam políticas que assegurem a preservação da cultura indigenista e que possibilitem, conjuntamente, fornecer serviços públicos de qualidade, garantir direitos e qualidade de vida digna (Paula, 2008). Consequentemente, pouco pode ser mudado se não houver o diálogo entre indígenas e governo; a participação desse povo deve ser presente e validada, pois não há outra maneira de compreender melhor as dificuldades se não pelos principais atores envolvidos nelas (Souza et al., 2007).

\section{Considerações Finais}

Como exposto durante o texto, o campo das políticas públicas é composto por um conjunto de ações, planos e atividades desenvolvidas pelo Estado com participação de atores estatais ou sociais para sanar problemas da sociedade, os quais atuam com o intuito de alcançar o interesse público e o bem-estar coletivo. Tais políticas estão vinculadas aos direitos garantidos, constitucionalmente e têm como objetivo assegurar resultados nos âmbitos social, cultural, econômico, ambiental, etc. No entanto, para que sejam efetivamente construídas, há a necessidade de que passem por algumas etapas, a saber: i.) definição da agenda, ii.) formulação da política, iii.) tomada de decisão, iv.) implementação e v.) avaliação.

No tocante às políticas públicas direcionadas aos povos indígenas, identificou-se o dever do Estado em desenvolver políticas diferenciadas que levem em consideração a cultura desses. Todavia, são notórias as dificuldades de inserir os indígenas na participação de todas as etapas do desenvolvimento. Normalmente, os povos indígenas são capazes de levar pautas para discussão e análise na agenda governamental, seja por meio de uma liderança da comunidade seja por meio de suas organizações representativas como as associações; entretanto, como destacado por alguns autores, não conseguem muitas vezes não conseguem participar das fases complementares da política pública entre a agenda e a implementação.

Portanto, para que os povos indígenas acessem políticas públicas que garantam seus direitos, é indispensável sua participação em todas as fases de política. Isto é, devem atuar como protagonistas em conjunto com o Estado e suas opiniões devem ser ouvidas antes de qualquer decisão no fluxo da política É importante salientar que o entendimento da participação 
indígena na política, é compreendida por meio da eficiência e capacidade do indivíduo em buscar melhores condições de vida, por isso são selecionadas pessoas capazes para representá-los.

A Funai - executora e coordenadora da política indigenista e o CNPI - instância de proposição de políticas públicas com participação indígena, dão suporte a políticas públicas indigenistas, levando em consideração a cultura indígena e a manutenção dela na atualidade. Espaços como esses devem ser fortalecimentos e ramificados para atender as populações indígenas nas mais variadas localizações geográficas em que se encontram, um grande desafio para a política pública.

Como outro ponto de apoio as causas indígenas, está a Articulação dos Povos Indígenas do Brasil (ABIP), foi criada pelo Acampamento Terra Livre (ATL), com o propósito de: i) unificar as lutas dos povos indígenas; ii) mobilizar organizações e povos indígenas contra agressões e ameaças aos direitos indígenas e iii) fortalecer a união dos povos indígenas entre as diferentes regiões e organizações indígenas do país.

Com o fim deste artigo, fica a cargo de novas pesquisas acerca da temática indígena, para identificar/levantar a participação e controle social dos povos indígenas na formulação de políticas públicas - de saúde, assistência social, educação, gestão territorial e previdenciário inerentes a eles e como as organizações indígenas e indigenistas apoiam as causas e lutas pelos seus direitos.

\section{Referências}

Agum, R., Riscado, P., \& Menezes, M. (2015). Políticas Públicas: Conceitos e Análise em Revisão. Revista Agenda Política, 3(2), 12-42. https://www.agendapolitica.ufscar.br/index.php/agendapolitica/article/view/67/63

Andrade, J. A., \& Silva, T. A. A. (Org.). (2017). O ensino da temática Indígena: subsídios didáticos para o estudo das sociodiversidades indígenas. Recife: Edições Rascunhos.

Ayala, C., \& Fehlauer, T. (2005). Considerações críticas sobre o conceito etnodesenvolvimento: para pensar a condescendência na relação intercultural. Tellus, 5(8/9), 37-51. http://dx.doi.org/10.20435/tellus.v0i8/9.94

Bergamaschi, M. A. (2008). Povos Indígenas: conhecer para respeitar. In Bittar, E.; Almeida, G. A. Curso de Filosofia do Direito. (6a ed.), Atlas.

Bicalho, E. B., Farias, B. M., Avelar, K. E. S., \& Dusek, P. M. (2018). O papel do estado-nação nas políticas públicas indígenas: a realidade brasileira. Revista da Seção Judiciária do Rio de Janeiro, 22(42), 131-150. https://doi.org/10.30749/2177-8337.v22n42p131-150

Bittar, E. C. B., \& Almeida, G. A. (2008). Curso de Filosofia do Direito. (6a ed.), Atlas.

Borges, J. C. (2016). “A sociedade brasileira nos fez pobres”: assistência social e autonomia étnica dos povos indígenas, o caso de Dourados, Mato Grosso do Sul. Horizontes Antropológicos, 22(46), 303-328. https://doi.org/10.1590/S0104-71832016000200011

Brasil, F. G., \& Capella, A. C. N. (2016). Os Estudos das Políticas Públicas no Brasil: passado, presente e caminhos futuros da pesquisa sobre análise de políticas. Revista Política Hoje, 25(1), 71-90. https://periodicos.ufpe.br/revistas/politicahoje/article/view/3710

Brito, A. G. L., Gomes, A. N. H., Castro, N. R. S., Pina, R. M. P., Siqueira, A. A. M. G., \& Rocha, E. S. C. (2020). Um olhar crítico-reflexivo sobre a saúde das populações indígenas utilizando a sistematização de experiências de Holliday. Research, Society and Development, 9(7), e822974656. https://doi.org/10.33448/rsd-v9i7.4656

Caminha, P. V. (1500). A Carta de Pero Vaz de Caminha. http://objdigital.bn.br/Acervo_Digital/livros_eletronicos/carta.pdf

Cardoso, M. D. (2014). Saúde e povos Indígenas no Brasil: notas sobre alguns temas equívocos na política atual. Caderno Saúde Política, $30(4)$, 860-866. http://dx.doi.org/10.1590/0102-311X00027814

Clastres, P. (2004). Do Etnocídio. In Clastres, P. Arqueologia da violência: pesquisas de antropologia política. Cosac Naify.

Cohn, C. (2001). Culturas em transformação: os índios e a civilização. São Paulo Perspec. 15(2), 36-42. https://doi.org/10.1590/S0102-88392001000200006

Coimbra Jr., C. E. A., Santos, R. V., \& Escobar, A. L., (Orgs.). (2005) Epidemiologia e saúde dos povos indígenas no Brasil [online]. Rio de Janeiro: Editora FIOCRUZ; ABRASCO.

Constituição da República Federativa do Brasil de 1988.(1988). Brasília, DF. http://www.planalto.gov.br/ccivil_03/constituicao/constituicao.htm

Costa e Silva, J. T. (2013). Processos de criação da política indigenista no estado da Bahia: atores e arranjos institucionais. Cadernos de Artes e Antropologia, 2(2), 71-85. https://doi.org/10.4000/cadernosaa.450

Costa, A. (1943). Indiologia. Biblioteca Militar. 
Costa, C. (2010). Sociologia: introdução à ciência da sociedade. Moderna.

Cruz, K. R., \& Coelho, E. M. B. (2012). A saúde indigenista e os desafios da particip(ação) indígena. Saúde Sociedade, 21(1), 185-198. http://dx.doi.org/10.1590/S0104-12902012000500016

Dantas, F. A. C. (2011). Direitos indígenas no Brasil: uma trajetória de violências e injustiças institucionalizadas. Revista Coletiva, 3(1). http://coletiva.labjor.unicamp.br/index.php/artigo/direitos-indigenas-no-brasil-uma-trajetoria-de-violencias-e-injusticas-institucionalizadas/

Declaração das Nações Unidas sobre os direitos dos povos indígenas. (2006). https://www.acnur.org/fileadmin/Documentos/portugues/BDL/De claracao_das_Nacoes_Unidas_sobre_os_Direitos_dos_Povos_Indigenas.pdf

Decreto $n^{\circ} 5.051$, de 19 de abril de 2004. (2004). Promulga a Convenção n ${ }^{\circ} 169$ da Organização Internacional do Trabalho - OIT sobre Povos Indígenas e Tribais. http://www.planalto.gov.br/ccivil_03/_ato2004-2006/2004/decreto/d5051.htm

Decreto $n^{\circ}$ 6.040, de 7 de fevereiro de 2007. (2007). Institui a Política Nacional de Desenvolvimento Sustentável dos Povos e Comunidades Tradicionais. http://www.planalto.gov.br/ccivil_03/_ato2007-2010/2007/decreto/d6040.htm

Decreto $n^{\circ}$ 6.861, de 27 de maio de 2009. (2009). Dispõe sobre a Educação Escolar Indígena, define sua organização em territórios etnoeducacionais, e dá outras providências. https://www.planalto.gov.br/ccivil_03/_ato2007-2010/2009/decreto/d6861.htm

Decreto $n^{\circ}$ 7.747, de 5 de junho de 2012. (2012). Institui a Política Nacional de Gestão Territorial e Ambiental de Terras Indígenas - PNGATI, e dá outras providências. www.planalto.gov.br/ccivil_03/_ato2011-2014/2012/decreto/d7747.htm

Decreto $n^{o} 8.593$, de 17 de dezembro de 2015. (2015). Dispõe sobre a criação do Conselho Nacional de Política Indigenista - CNPI e dá outras providências. www.planalto.gov.br/ccivil_03/_Ato2015-2018/2015/Decreto/D8593.htm.

Dye, T. D. (2016). Understanding Public Policy. (15a ed.), Pearson.

Ferrari, R. (2015). Writing narrative style literature reviews. Medical Writing, 4(24), 230-234. 10.1179/2047480615Z.000000000329

Fernandes, F. R., \& Uribe, M. A. D. (2019). Movimentos indígenas latino-americanos da segunda metade do século XX: reflexões comparativas sobre processos decoloniais no Brasil e na Colômbia. Tellus, 19(39), 71-104. http://dx.doi.org/10.20435/tellus.v19i39.539.

Ferreira, A. C. (2007). Tutela, Resistência e Co-gestão Indígena: relações de poder entre os índios Terena e o Estado brasileiro. Anais do Congresso Brasileiro de Sociologia, Recife, PE, Brasil, 13.

Fonseca, F. (2013). Dimensões críticas das políticas públicas. Cadernos EBAPE, 11(3), 402-418. https://doi.org/10.1590/S1679-39512013000300006

Fonseca, K. N. O., \& Weigel, V. A. C. M. (2018). Fundamentos e perspectivas para educação escolar Indígena. Revista Triângulo, 11(1), 235-247. https://doi.org/10.18554/rt.v0i0.2686

Funai - Fundação Nacional do Índio. Histórico: Comissão Nacional de Política Indigenista. http://www.funai.gov.br/index.php/cnp i1/informativo?limitstart=0\#

Gomes, M. P. (1988). Os índios e o Brasil: Ensaio sobre um holocausto e sobre uma nova possibilidade de convivência. Vozes.

Guirau, K. M., \& SILVA, C. R. (2013). Povos Indígenas no espaço urbano e políticas públicas. UNESP, 2013.

Holanda, F. C. C. (2015). Políticas públicas e etnodesenvolvimento com enfoque na legislação indigenista brasileira. Revista Brasileira de Políticas Públicas, 5(Número Especial), 374-390. https://doi.org/10.5102/rbpp.v5i2.3376

I Conferência Nacional de Política Indigenista. (2016). Total de propostas aprovadas pela etapa nacional. http://www.funai.gov.br/arquivos/conteudo/ascom/2017/03-mar/01PropostasTotaisEtapaNacional.pdf

IBGE - Instituto Brasileiro de Geografia e Estatística. (2010). Indígenas. https://indigenas.ibge.gov.br/

IBGE - Instituto Brasileiro de Geografia e $\quad$ Estatística. $\quad$ (2017). https://censos.ibge.gov.br/agro/2017/templates/censo_agro/resultadosagro/index.html

Jesson, J. K., Matheson, L. \& Lacey F. M. (2011). Doing your literature review: traditional and systematic techniques. Sage Publications.

Lei $n^{o}$ 2.889, de $1^{o}$ de outubro de 1956. (1956). Define e pune o crime de genocídio. https://legislacao.presidencia.gov.br/atos/?tipo=LEI\&numero=2889\&ano=1956\&ato=fc1oXW650dNRVT8e3

Lei $n^{\circ}$ 6.001, de 19 de dezembro de 1973. (1973). Dispõe sobre o Estatuto do Índio. http://www.planalto.gov.br/ccivil_03/Leis/L6001.htm

Lei $n^{\circ}$ 9.836, de 23 de setembro de 1999. (1999). Acrescenta dispositivos à Lei no 8.080, de 19 de setembro de 1990, que "dispõe sobre as condições para a promoção, proteção e recuperação da saúde, a organização e o funcionamento dos serviços correspondentes e dá outras providências", instituindo o Subs istema de Atenção à Saúde Indígena. http://www.planalto.gov.br/ccivil_03/leis/L9836.htm

Lima, L. G. B. (2016). Os Akwẽ-Xerente no Tocantins: território Indígena e as questões socioambientais. Tese de doutorado, Universidade de São Paulo, Brasil

Lopes, D. B. (2014). O direito dos índios no Brasil: a trajetória dos grupos Indígenas nas constituições do país. Espaço Ameríndio, 8(1), 83-108. https://doi.org/10.22456/1982-6524.41524 
Lopes. B., Amaral, J. N., \& Caldas, W. (2008). Políticas Públicas: conceitos e práticas. Sebrae/MG.

Luciano, G. S. (2006). O Índio brasileiro: o que você precisa saber sobre os povos indígenas no Brasil de hoje. Brasília: Ministério da Educação, Secretaria de Educação Continuada, Alfabetização e Diversidade, LACED/Museu Nacional.

Matos, R. S., Alves, M. J. S., Coutinho, J. S., Santos, M. S., Sousa, M. A., Nascimento, M. C. C., \& Barros, T. M. M. C. (2019). Manual de Critérios para a Elaboração das Políticas Públicas. São Luiz: Governo do Estado, Secretaria de Estado do Planejamento e Orçamento.

Mello, L. J. A. (2018). Políticas Públicas e Participação: Políticas Públicas e Governo Local. ENAP.

Mello, R. (2001). Meninos do mangue. Schwarcz.

Mendonça, D. G., \& Oliveira, R. M. da S. R. (2020). Educação indígena no Brasil: Entre legislações, formação docente e tecnologias. Research, Society and Development, 9(8), e518985564. https://doi.org/10.33448/rsd-v9i8.5564

Moraes, J. T. (2018). O subsistema de atenção à saúde indígena e sua efetivação no estado de Mato Grosso do Sul: análise do funcionamento, ações e serviços. Revista Juris UniToledo, 3(4), 191-203. http://ojs.toledo.br/index.php/direito/article/view/3095/383

Moraes, N. R., Campos, A. C., Müller, N. M., Gamba, F. B., Gamba, M. F. D. D. F. (2017). As comunidades tradicionais e a disc ussão sobre o conceito de território. Revista Espacios, 38(12), 17-25. http://www.revistaespacios.com/a17v38n12/a17v38n12p17.pdf

Nader, P. (2019). Filosofia do Direito. (26a ed.), Forense.

Nimuendajú, C. (2017). Mapa etno-histórico do Brasil e regiões adjacentes. (2a ed.), IPHAN, IBGE.

Patton, M. Q. (2015). Qualitative research and evaluation methods: integrating theory and practice. Fourth Edition. United States of America: Sage Publications.

Paula, J. M. (2008). Políticas públicas e as populações indígenas de Rondônia. Revista Geografias, 4(1), 71-80. https://periodicos.ufmg.br/index.php/geografias/article/view/13242

Pereira, T. S. L., \& Brasileiro, T. S. A. (2016). Políticas públicas educacionais e escolarização Indígena. Revista Educação e Emancipação, 9(3), 218-250. http://dx.doi.org/10.18764/2358-4319.v9n3p218-250.

Portaria do Ministério da Saúde $n^{\circ}$ 254, de 31 de janeiro de 2002. (2002). Política Nacional de Atenção à Saúde dos Povos Indígenas. http://www.funasa.gov.br/site/wp-content/files_mf/Pm_254_2002.pdf

Quaresma, F. J. P., \& Ferreira, M. N. O. (2013). Os povos indígenas e a educação. Revista Práticas de Linguagem, 3(2), 235-246. https://www.ufjf.br/praticasdelinguagem/files/2014/01/234-\%e2\%80\%93-246-Os-povos-ind\%c3\%adgenas-e-a-educa\%c3\%a7\%c3\%a3o.pdf

Ramos, F. P. (2014). O apogeu e declínio do ciclo das especiarias (1500-1700). Clube de Autores.

Rangel, L. H. V. (2013). Política Indigenista. In Giovanni, G., Nogueira, M. A. (Orgs.). Dicionário de Políticas Públicas. FUNDAP/ Imprensa Oficial do Estado de São Paulo.

Rocha, A. A. B. M. (2012). A importância da implementação para a análise das políticas públicas. Revista Pensamento e Realidade, 27(1), 3-18, 2012. https://revistas.pucsp.br/index.php/pensamentorealidade/article/view/11521/8337

Rodrigues, J. A., Lima, A. T., Sanches, M. E. S., Souza, I. M. S., \& Moraes, N. R. (2018). Demarcação das terras indígenas no oeste paulista: formação da Aldeia Índia Vanuíre (Arco-Íris/Estado de São Paulo/Brasil). In Baptista, R. D., Porto Júnior, F. G. R., Lima, A. T., Souza, F. C., Pechula, L. C. (Orgs.). Povos Originários e Comunidades Tradicionais: Trabalhos de pesquisa e de extensão universitária. Editora Fi, Boa Vista: Editora da UFRR.

Rodrigues, L. R., \& Thé, A. P. G. (2012). Comunidades tradicionais: sujeitos de direito entre o desenvolvimento e a sustentabilidade. Anais do Congresso Internacional Interdisciplinar em Sociais e Humanidades, Niterói, RJ, Brasil, 1.

Rua, M. G. (1998). Análise de políticas públicas: conceitos básicos. In Rua, M. G.; Carvalho, M. I. V. (Orgs.). O estudo da política: tópicos selecionados. Brasília, DF: Paralelo 15.

Rua, M. G. (2013). Para aprender políticas públicas. IGPEP.

Rua, M. G. (2014). Políticas Públicas. (3a ed.), Florianópolis: Departamento de Ciências da Administração/UFSC; CAPES: UAB, 2014.

Salazar, K. (2018). Manual para defender os direitos dos povos indígenas e tradicionais. Fundação para o devido processo.

Santos, E. L., Caíres, F. C. B., Santana, W. G. P., \& Batista, F. S. S. (2011). Análise de Políticas Públicas: a Experiência do ProJovem Urbano na Cidade de Vitória da Conquista - BA. Anais do Encontro da ANPAD, 35.

Santos, M. P. G. (2016). Políticas públicas e sociedade. 3.d. Florianópolis: Departamento de Ciências da Administração / UFSC; Brasília: CAPES: UAB, 2016. 100p.

Santos, V. F. (2012). Cultura Indígena de Roraima em Busca de Identidade. Revista Eletrônica de Ciências Sociais, História e Relações Internacionais, 5(1), 1-10. http://dx.doi.org/10.18227/1983-9065ex.v5i1.1449

Schwingel, L. R. (2002). Povos Indígenas e políticas públicas da assistência social no Rio Grande do Sul: subsídios para a construção de políticas públicas diferenciadas às Comunidades Kaingang e Guarani. Rio Grande do Sul: Secretaria do Trabalho, Cidadania e Assistência Social - STCAS 
Secchi, L. (2013). Políticas públicas: conceitos, esquemas de análise, casos práticos. (2a ed.), Cengage Learning.

Serafim, M. P., Dias, R. B. (2012). Análise de política: uma revisão da literatura. Cadernos Gestão Social, 3(1), 121-134. https://periodicos.ufba.br/index.php/cgs/article/view/31562/pdf_22

Shiraishi Neto, J. (2007). Direito dos povos e das comunidades tradicionais no Brasil: declarações, convenções internacionais e dispositivos jurídicos definidores de uma política nacional. Manaus: UEA.

Silva Júnior, G. L., \& Souza, R. M. (2009). As comunidades tradicionais e a luta por direitos étnicos e coletivos no sul do Brasil. Revista da Faculdade de Direito da UFG, 33(2), 128-142. https://doi.org/10.5216/rfd.v33i2.9862.

Silva, F. B. (2017). Política nacional da saúde indígena e educação escolar indígena: uma análise de conting ências. Dissertação de Mestrado, Universidade Estadual Paulista "Júlio de Mesquita Filho", Bauru, SP, Brasil.

Silva, P. L. B., \& Melo, M. A. B. (2000). O processo de implementação de políticas públicas no Brasil: características e determinantes da avaliação de programas e projetos. Caderno do Núcleo de Estudos de Políticas Públicas-NEEP Unicamp, 48, 1-14. https://www.nepp.unicamp.br/biblioteca/periodicos/issue/view/143/CadPesqNepp48

Silva, R. H., \& Kuhn Júnior, N. (2018). As políticas públicas e o protagonismo indígena: uma interlocução necessária. Revista Direitos Culturais, 13(31), 1942. http://dx.doi.org/10.20912/rdc.v13i31.2390

Silva, T. T. (2009). A produção social da identidade e da diferença. In Silva, T. T., Hall, S., \& Woodwar, K (Org.). Identidade e diferença: a perspectiva dos estudos culturais. Vozes

Souza Filho, C. F. M., \& Bergold, R. C. (2013). Os direitos dos povos indígenas no Brasil: desafios no século XXI. Letra da Lei.

Souza, C. N. I., Lima, A. C. S., Almeida, F. V. R., \& Wentzel, S. (2007). Povos indígenas: projetos e desenvolvimento. Contra Capa Livraria.

Souza, F. C., Barrozo, P., Ruiz, S. C. M., \& Moraes, N. R. (2017). Políticas Públicas: Estatuto Científico. In Porto Júnior, F. G. R., Baptista, R. D., \& Souza, F. C. (Orgs.) Convergências entre os campos da comunicação, democracia e gestão social: volume 2. Editora Fi.

Souza, F. C., Quiqueto, A. M. B., Lena, M. B. A., Santi, V. J. C. \& Moraes, N. R. (2021). Etnodesenvolvimento e bem viver: concepções e implicações para políticas públicas. Research, Society and Development, 10(2), https://rsdjournal.org/index.php/rsd/article/view/12860/11520. 10.33448/rsd-v10i2.12860.

Souza, F. C.; Moraes, N. R.; Quiqueto, A. M.; \& Teodoro, V. B. (2020). COVID-19 AND INDIGENOUS PEOPLES: Aspects of social security. Revista Observatório, 6 (2), 1-27. doi: https://doi.org/10.20873/uft.2447-4266.2020v6n2a12en.

Souza, I. R. C. S., \& Bruno, M. M. G. (2013). Políticas de educação no contexto indígena: discursos e práticas. Revista Educação e Políticas em Debate, 2(1), 209-228. http://www.seer.ufu.br/index.php/revistaeducaopoliticas/article/view/24067/13267

Tenório, E. C. H., \& Santos, J. M. (2018). Reflexões sobre o processo de implementação da política pública de saúde no Brasil. Espaço Público, 2, 18-25. https://periodicos.ufpe.br/revistas/politicaspublicas/article/view/238593/30375

Viana, A. L. (1996). Abordagens metodológicas em políticas públicas. Revista de Administração Pública, 30(2), 5-43. http://bibliotecadigital.fgv.br/ojs/index.php/rap/article/view/8095

Vicente, E. F., Moraes, N. R., Rodrigues, J. A., \& Pires, B. R. C. (2017). Apontamentos sobre a cultura das comunidades tradicionais da região de Tupã: Aldeia Indígena Vanuíre (Arco Íris/SP) e Comunidade Leta de Varpa (Tupã/SP). In Porto Júnior, F. G. R., Baptista, R. D., Souza, F. C. (Orgs.) Convergências entre os campos da comunicação, democracia e gestão social: volume 2. Editora Fi.

Wandscheer, C. B., \& Bessa, F. L. B. N. (2009). Direitos Indígenas e políticas públicas: análise a partir de uma realidade multicultural. Revista Direitos Culturais, 4(6), 123-140. 10.20912/rdc.v4i6.25

Weber, M. (2001). Textos Coligidos. Ática.

Weber, M. (2008). Os Três Tipos Puros de Dominação Legítima. VGuedes Multimídia.

Weber, M. (2009). Economia e Sociedade: fundamentos da sociologia compreensiva. (4a ed.), Editora Universidade de Brasília.

Wu, X., Ramest, M., Howllet, M., \& Fritzen, S. (2014). Guia de políticas públicas: gerenciando processos. ENAP. 